\title{
Response
}

\section{Predictors of the Therapeutic Efficacy and Consideration of the Best Combination Therapy of Sodium-Glucose Co-transporter 2 Inhibitors (Diabetes Metab J 2019;43: 158-73)}

\author{
Ji-Yeon Lee, Eun Seok Kang \\ Department of Internal Medicine, Yonsei University College of Medicine, Seoul, Korea
}

We would like to express our gratitude to Dr. Kim for his interest and commentary about our recently published article "Predictors of the therapeutic efficacy and consideration of the best combination therapy of sodium-glucose co-transporter 2 inhibitors" [1].

We agree with Dr. Kim's concern that we should be cautious in concluding that low body mass index (BMI) in well-controlled diabetes is associated with the good response of sodium-glucose co-transporter 2 (SGLT-2) inhibitor. The number of subjects with low BMI and well-controlled diabetes was small, and there are no studies so far that reported similar results. In previous studies, however, the subjects were classified by one factor (e.g., baseline BMI $<25$ and $\geq 25 \mathrm{~kg} / \mathrm{m}^{2}$ ) rather than a combination of two factors [2]. In addition, Asians have lower BMI than Caucasians and there may be differences in response to anti-diabetic drugs due to ethnicity. Further studies with larger populations are needed to better understand the impacts of SGLT-2 inhibitors in the Korean population.

Regarding the comment about the combination of a dipeptidyl peptidase-4 (DPP-4) inhibitor and an SGLT-2 inhibitor, the present study could not compare the glucose lowering efficacy between subjects who added a DPP-4 inhibitor to a baseline SGLT-2 inhibitor and those who added an SGLT-2 inhibitor to a baseline DPP-4 inhibitor. However, the choice of a second and third additional drug should be individualized for each patient. A DPP-4 inhibitor would be preferred in elderly patients or those with renal impairment [3]. On the other hand, an SGLT-2 inhibitor showed beneficial effects in patients with high cardiovascular risk $[4,5]$.

Finally, as commented, the number of subjects in each triple combination therapy was different due to the Korean insurance, and this should be considered when interpreting the results. More research on the combination therapy using an SGLT-2 inhibitor should establish better insurance standards and lead to effective diabetes treatment.

\section{CONFLICTS OF INTEREST}

No potential conflict of interest relevant to this article was reported.

\section{REFERENCES}

1. Lee JY, Cho Y, Lee M, Kim YJ, Lee YH, Lee BW, Cha BS, Kang ES. Predictors of the therapeutic efficacy and consideration of the best combination therapy of sodium-glucose co-transporter 2 inhibitors. Diabetes Metab J 2019;43:158-73.

2. Strojek K, Yoon KH, Hruba V, Elze M, Langkilde AM, Parikh S.
Corresponding author: Eun Seok Kang (D) https://orcid.org/0000-0002-0364-4675 Department of Internal Medicine, Yonsei University College of Medicine, 50-1 Yonsei-ro, Seodaemun-gu, Seoul 03722, Korea

E-mail: edgo@yuhs.ac
This is an Open Access article distributed under the terms of the Creative Commons Attribution Non-Commercial License (http://creativecommons.org/licenses/by-nc/4.0/) which permits unrestricted non-commercial use, distribution, and reproduction in any medium, provided the original work is properly cited. 
Effect of dapagliflozin in patients with type 2 diabetes who have inadequate glycaemic control with glimepiride: a randomized, 24-week, double-blind, placebo-controlled trial. Diabetes Obes Metab 2011;13:928-38.

3. Scheen AJ. Safety of dipeptidyl peptidase- 4 inhibitors for treating type 2 diabetes. Expert Opin Drug Saf 2015;14:505-24.

4. Zinman B, Wanner C, Lachin JM, Fitchett D, Bluhmki E, Hantel S, Mattheus M, Devins T, Johansen OE, Woerle HJ, Broedl
UC, Inzucchi SE; EMPA-REG OUTCOME Investigators. Empagliflozin, cardiovascular outcomes, and mortality in type 2 diabetes. N Engl J Med 2015;373:2117-28.

5. Neal B, Perkovic V, Mahaffey KW, de Zeeuw D, Fulcher G, Erondu N, Shaw W, Law G, Desai M, Matthews DR; CANVAS Program Collaborative Group. Canagliflozin and cardiovascular and renal events in type 2 diabetes. N Engl J Med 2017;377: 644-57. 